Communication

\title{
Iron, Anemia, and Iron Deficiency Anemia among Young Children in the United States
}

\author{
Priya M. Gupta *, Cria G. Perrine, Zuguo Mei and Kelley S. Scanlon \\ Division of Nutrition, Physical Activity, and Obesity, Centers for Disease Control and Prevention, Atlanta, \\ GA 30341, USA; hgk3@cdc.gov (C.G.P.); zam0@cdc.gov (Z.M.); kxs5@cdc.gov (K.S.S.) \\ * Correspondence: kso7@cdc.gov; Tel.: +1-908-418-0970
}

Received: 13 April 2016; Accepted: 26 May 2016; Published: 30 May 2016

\begin{abstract}
Iron deficiency and anemia are associated with impaired neurocognitive development and immune function in young children. Total body iron, calculated from serum ferritin and soluble transferrin receptor concentrations, and hemoglobin allow for monitoring of the iron and anemia status of children in the United States. The purpose of this analysis is to describe the prevalence of iron deficiency (ID), anemia, and iron deficiency anemia (IDA) among children 1-5 years using data from the 2007-2010 National Health and Nutrition Examination Survey (NHANES). Prevalence of ID, anemia, and IDA among children $1-5$ years was $7.1 \%(5.5,8.7), 3.9 \%(2.0,4.3)$, and $1.1 \%(0.6,1.7)$, respectively. The prevalence of both ID and anemia were higher among children $1-2$ years $(p<0.05)$. In addition, $50 \%$ of anemic children 1-2 years were iron deficient. This analysis provides an update on the prevalence of ID, anemia, and IDA for a representative sample of US children. Our results suggest little change in these indicators over the past decade. Monitoring of ID and anemia is critical and prevention of ID in early childhood should remain a public health priority.
\end{abstract}

Keywords: iron deficiency; anemia; NHANES

\section{Introduction}

Iron deficiency (ID) is the most common nutritional deficiency in the world and infants and young children are at the highest risk [1]. Iron deficiency in young children significantly increases the risk of developmental delays and behavioral disturbances. It is also known to cause iron deficiency anemia (IDA) [2].

The objective for this analysis is to provide an update on the prevalence of ID, anemia, and IDA among children $1-5$ years in the United States.

\section{Materials and Methods}

We analyzed data from the 2007-2010 National Health and Nutrition Examination Survey (NHANES), a cross-sectional survey representative of the total non-institutionalized civilian population in the United States. NHANES uses a stratified multistage, probability design to select participants and is conducted via household interviews and standardized examinations in the NHANES mobile examination centers $[3,4]$.

Children 1-5 years (12-71.9 months) who had complete nutritional biochemistry data on serum transferrin receptor (sTfR), ferritin, and hemoglobin were included in our analysis $(n=1156)$. Starting in 2004, serum ferritin and sTfR concentrations were measured by the RocheTina-quant immunoturbidimetric assay on the Hitachi 912 clinical analyzer Roche Diagnostics. Hemoglobin was measured as part of a complete blood count done on the Coulter ${ }^{\circledR}$ HMW [5-7]. Total body iron (TBI) 
is the suggested indicator for ID in the United States [8]. We calculated TBI on the basis of sTfR and ferritin concentrations through Equation (1) [5,9]:

$$
\mathrm{TBI}(\mathrm{mg} / \mathrm{kg})=-[\log 10(\mathrm{sTfR} \times 1000 / \text { ferritin })-2.8229] / 0.1207
$$

For this calculation we converted Roche sTfR concentrations to those equivalent to the Flowers assay used in the development of the body iron model [5,10], see Equation (2):

$$
\text { Flowers sTfR }=1.5 \times \text { Roche } \mathrm{sTfR}+0.35 \mathrm{mg} / \mathrm{L}
$$

ID was defined as TBI $<0 \mathrm{mg} / \mathrm{kg}$. Anemia was defined as hemoglobin concentration $<11.0 \mathrm{~g} / \mathrm{dL}$ for children 6-59 months and $<11.5 \mathrm{~g} / \mathrm{dL}$ for children 60-72 months [11,12]. IDA was defined as having both anemia and ID. Estimates were weighted and take into account NHANES complex survey design. We used chi square tests to assess whether prevalence estimates varied by age.

\section{Results}

Among children aged 1-5 years, median total body iron was $4.0 \mathrm{mg} / \mathrm{kg}(95 \%$ CI: 3.9, 4.2) and mean hemoglobin was $12.6 \mathrm{~g} / \mathrm{dL}$ (95\% CI: $12.5,12.7)$. Among children aged $1-5$ years, $7.1 \%$ were iron deficient. The prevalence of anemia and IDA were $3.9 \%$ and $1.1 \%$, respectively (Table 1) Approximately $28 \%$ of children who were anemic were iron deficient.

Table 1. Prevalence of Iron Deficiency, Anemia, and Iron Deficiency Anemia among Children 1-5 years

\begin{tabular}{|c|c|c|c|c|c|c|c|}
\hline & \multirow{2}{*}{$n$} & \multicolumn{2}{|c|}{ Iron Deficiency $^{1}$} & \multicolumn{2}{|r|}{ Anemia ${ }^{2}$} & \multicolumn{2}{|c|}{ Iron Deficiency Anemia ${ }^{3}$} \\
\hline & & $\%$ & $\begin{array}{l}\text { 95\% Confidence } \\
\text { Interval }\end{array}$ & $\%$ & $\begin{array}{c}\text { 95\% Confidence } \\
\text { Interval }\end{array}$ & $\%$ & $\begin{array}{l}\text { 95\% Confidence } \\
\text { Interval }\end{array}$ \\
\hline $\begin{array}{c}1-5 \text { years } \\
(12-71.9 \text { months })\end{array}$ & 1437 & 7.1 & $(5.5,8.7)$ & 3.9 & $(2.5,5.3)$ & 1.1 & $(0.6,1.7)$ \\
\hline $\begin{array}{c}1-2 \text { years } \\
(12-35.9 \text { months })\end{array}$ & 643 & 13.5 * & $(9.8,17.2)$ & $5.4^{*}$ & $(3.5,7.4)$ & 2.7 & $(1.2,4.2)$ \\
\hline $\begin{array}{c}3-5 \text { years } \\
\text { (36-71.9 months) }\end{array}$ & 794 & 3.7 & $(1.9,5.5)$ & 3.1 & $(1.4,4.7)$ & $-* *$ & - \\
\hline
\end{tabular}
in the United States, National Health and Nutrition Examination Survey (NHANES) 2007-2010.

${ }^{1}$ Iron deficiency was defined as total body iron (TBI) $<0 \mathrm{mg} / \mathrm{kg} ;{ }^{2}$ Anemia was defined as hemoglobin concentration $<11.0 \mathrm{~g} / \mathrm{dL} ;{ }^{3}$ Iron deficiency anemia was defined as having both anemia and iron deficiency; * Chi. Square test $p$-value $<0.05$ for differences between children $1-2$ years and 3-5 years; ${ }^{* *}$ The Centers for Disease Control and Prevention's National Center for Health Statistics does not support presenting estimates when relative standard errors (standard error of prevalence/prevalence) are $\geqslant 30 \%$ so this estimate was suppressed [13].

The prevalence of ID was higher among children aged $1-2$ years $(p<0.05)$. Among younger children, $5.4 \%$ were anemic and $2.7 \%$ had IDA. Therefore, approximately $50 \%$ of children $1-2$ years who were anemic were iron deficient.

\section{Discussion}

This analysis provides an update on the iron and anemia status of children 1-5 years in the United States. Previous analysis of NHANES 2003-2006 data showed that $14.4 \%$ of children 1-2 years and $3.7 \%$ of children $3-5$ years were iron deficient [14]. Our results are similar and confirm that ID among young children in the United States remains a public health concern. Extrapolation of the prevalence estimate of ID to U.S. census data suggests that approximately 1.5 million children between the ages of 1 and 5 years may be at risk for iron deficiency. Although the definition of anemia differed slightly for children $24-59$ months ( $\leqslant 111 \mathrm{~g} / \mathrm{L}$ vs. $\leqslant 110 \mathrm{~g} / \mathrm{L}$ ), an analysis, of children $12-59$ months (1-4 years), using NHANES 1999-2002 data found that 3.6\% were anemic and the prevalence of IDA was 1.2\% (Iron deficiency anemia was defined as "anemia plus abnormal value $\geqslant 2$ : serum ferritin, transferrin 
saturation, and erythrocyte protoporphyrin") [11]. Our results showing the prevalence of anemia and IDA, among children $1-5$ years, as $3.9 \%$ and $1.1 \%$ respectively, suggests little change in these indicators over the past decade. Iron deficiency and anemia are associated with impaired psychomotor and neurocognitive development as well as impaired immune function in children and often these consequences are irreversible [15-18]. Therefore, prevention of ID in early childhood should remain a public health priority.

Acknowledgments: All sources of funding of the study should be disclosed. Please clearly indicate grants that you have received in support of your research work. Clearly state if you received funds for covering the costs to publish in open access.

Author Contributions: P.M.G., C.G.P., Z.M., K.S.S. designed the research question, analyzed data, reviewed statistical analysis, and wrote the paper. All authors have read and approved the final manuscript.

Conflicts of Interest: The authors declare no conflict of interest.

\section{Abbreviations}

The following abbreviations are used in this manuscript:

ID Iron deficiency

IDA Iron deficiency anemia

STfR Serum transferrin receptor

\section{References}

1. Looker, A.C.; Dallman, P.R.; Carroll, M.D.; Gunter, E.W.; Johnson, C.L. Prevalence of iron deficiency in the United States. JAMA 1997, 277, 973-976. [CrossRef] [PubMed]

2. Centers for Disease Control and Prevention (CDC). Recommendations to Prevent and Control Iron Deficiency in the United States; MMWR, Centers for Disease Control and Prevention (CDC): Atlanta, GA, USA, 1998.

3. Centers for Disease Control and Prevention (CDC); National Center for Health Statistics. 2007-2008 National Health and Nutrition Examination Survey (NHANES); US Department of Health and Human Services, Centers for Disease Control and Prevention: Hyattsville, MD, USA, 2007.

4. Centers for Disease Control and Prevention (CDC); National Center for Health Statistics. 2009-2010 National Health and Nutrition Examination Survey (NHANES); US Department of Health and Human Services, Centers for Disease Control and Prevention: Hyattsville, MD, USA, 2009.

5. Cook, J.D.; Flowers, C.H.; Skikne, B.S. The quantitative assessment of body iron. Blood 2003, 101, 3359-3364. [CrossRef] [PubMed]

6. National Center for Health Statistics. National Health and Nutrition Examination Survey (NHANES) 2007-2008. Lab Methods. Available online: http://www.cdc.gov/nchs/nhanes/nhanes2007-2008/lab_ methods_07_08.htm (accessed on 6 November 2015).

7. National Center for Health Statistics. National Health and Nutrition Examination Survey (NHANES) 2009-2010. Lab Data. Available online: http://wwwn.cdc.gov/nchs/nhanes/search/datapage.aspx? Component=laboratory\&CycleBeginYear=2009 (accessed on 6 November 2015).

8. Cusick, S.E.; Looker, A.C.; Cogswell, M.E.; Pfeiffer, C.M.; Grummer-Strawn, L. Iron-status indicators. Pediatrics 2008, 121, 651-652. [CrossRef] [PubMed]

9. World Health Organization (WHO); Centers for Disease Control and Prevention (CDC). Assessing the Iron Status of Populations. 2007. Available online: http://www.who.int/nutrition/publications/micronutrients/ anaemia_iron_deficiency/9789241596107/en/(accessed on 6 November 2015).

10. Skikne, B.; Flowers, C.; Cook, J. Serum transferrin receptor: A quantitative measure of tissue iron deficiency. Blood 1990, 75, 1870-1876. [CrossRef] [PubMed]

11. Cusick, S.E.; Mei, Z.; Freedman, D.S.; Looker, A.C.; Ogden, C.L.; Gunter, E.; Cogswell, M.E. Unexplained Decline in the prevalence of anemia among US children and women between 1988-1994 and 1999-2002. Am. J. Clin. Nutr. 2008, 88, 1611-1617. [CrossRef] [PubMed]

12. World Health Organization (WHO); United Nations International Children's Emergency Fund (UNICEF). Iron Deficiency Anaemia: Assessment, Prevention, and Control: A Guide for Programme Managers; World Health Organization: Geneva, Switzerland, 2001. 
13. National Center for Health Statistics (NCHS). NHANES 1999-2000 Addendum to the NHANES III Analytic Guidelines. Available online: https://www.cdc.gov/nchs/data/nhanes/guidelines1.pdf (accessed on 6 November 2015).

14. Cogswell, M.E.; Looker, A.C.; Pfeiffer, C.M.; Cook, J.D.; Lacher, D.A.; Beard, J.L.; Lynch, S.R.; Grummer-Strawn, L.M. Assessment of iron deficiency in us preschool children and nonpregnant females of childbearing age: National Health and Nutrition Examination Survey 2003-2006. Am. J. Clin. Nutr. 2009, 89, 1334-1342. [CrossRef] [PubMed]

15. Walter, T. Effect of iron-deficiency anemia in cognitive skills and neuromaturation in infancy and childhood. Food Nutr. Bull. 2003, 24, 104-110. [CrossRef]

16. Pasricha, S.R.; Hayes, E.; Kalumba, K.; Biggs, B.A. Effect of daily iron supplementation on health in children aged 4-23 months: A systematic review and meta-analysis of randomised controlled trials. Lancet Glob. Health 2013, 1, 77-86. [CrossRef]

17. Murray-Kolb, L.E. Iron supplementation in early life and child health. Lancet Glob. Health 2013, 1, 56-57. [CrossRef]

18. Murray-Kolb, L.E. Iron and brain functions. Curr. Opin. Clin. Nutr. Metab. Care 2013, 16, 703-707. [CrossRef] [PubMed]

(C) 2016 by the authors; licensee MDPI, Basel, Switzerland. This article is an open access article distributed under the terms and conditions of the Creative Commons Attribution (CC-BY) license (http://creativecommons.org/licenses/by/4.0/). 